\section{UNIVERSITÄT \\ $D_{E} U_{S} I_{S} S_{E} B_{N} U^{R} G$}

Chair for Management Sciences and Energy Economics

Prof. Dr. Christoph Weber

Chair for Management Sciences and Energy Economics

University of Duisburg-Essen

EWL Working Paper No. 02/12

\title{
An Evaluation of Different Approaches to Capital Structure Regulation
}

by

Stephan Schaeffler

June 4, 2012 


\title{
An Evaluation of Different Approaches to Capital Structure Regulation
}

\author{
Stephan Schaeffler
}

\begin{abstract}
With the introduction of incentive regulation in many network industries, different approaches how to remunerate invested capital have been used. Under incentive regulation, many regulators remunerate the regulated asset base with a weighted average cost of capital (WACC) based on a pre-defined gearing, not considering individual capital structure at all. From a regulator's point of view, the aim is clear: Provide incentives to the firms to optimize their capital structure, i.e. finding the right balance between equity financing and debt. Taggert (1981) shows that rate-of-return regulation creates an incentive for regulated firms to alter their capital structures in order to influence consumer prices. Spiegel and Spulber (1994) find that the firm chooses its equity and debt in order to affect the outcome of the regulatory process. As a hybrid model between WACC and individual capital structure, the German Regulator sets incentives for a certain capital structure by limiting the return on equity that can be incorporated into network tariffs with a cap. However it has not been analyzed neither in theoretical nor in practical research which incentives are really created by this cap.

To analyze the impact of different capital structure regulation mechanisms on the optimal capital structure, a static trade-off-theory model of capital structure is presented and the characteristics of several different approaches to capital structure regulation and their characteristics are analyzed. The results indicate that the overall effect of capital structure regulation is very important: In an ex-ante regulation setting, the consideration of individual capital structures leads to higher equity ratios than the use of a benchmark-WACC. In this context, caps are an effective mean to set incentives for a predefined equity ratio. In an ex-post regulation where bankruptcy is merely a threat, it may be optimal to rely on extreme strategies solely financing with equity or debt.
\end{abstract}

Keywords: Capital structure, trade-off theory, network operators, regulation, cost of equity JEL-Classification: G32, G38, L9

STEPHAN SCHAEFFLER

Horváth \& Partners Management Consultants

(Ganghoferstr. 39, 80339 München)

++49 - (0)89 / 544625-15

www.horvath-partners.de

sschaeffler@horvath-partners.com

The author is sorely responsible for the contents which do not necessarily represent the opinion of the Chair for Management and Energy Economics. 


\section{Introduction}

With the introduction of incentive regulation in many regulated network industries, different approaches how to remunerate invested capital have been used. From a regulator's point of view, the aim is clear: Provide incentives to the firms to optimize their capital structure, i.e. finding the right balance between equity financing and debt. Taggert (1981) shows that rateof-return regulation creates an incentive for regulated firms to alter their capital structures in order to influence consumer prices. If the regulator's price setting rule depends in some predictable way on capital structure of the firm, the company will choose the financing mix in order to increase prices moving closer to monopoly prices. If this argument is taken seriously, regulators must consider capital structure in their regulation scheme.

The regulation of capital structure has not been a topic of intense research. De Fraja and Stones (2004) summarize that existing literature on the topic "takes a point of view probably suited to the American situation, where most regulated firms are long established, and where, typically, regulators do take the capital structure as given". With regards to the actual situation in Europe, Legal Unbundling for transmission and distribution network operators has led to the founding of hundreds of new companies each with its own capital structure. From 2008 until 2011, E.ON AG ('Transpower', sold to Tennet), RWE AG ('Amprion', partially sold to financial investors) and Vattenfall Europe AG ('50 Hertz', sold to Elia and ICM) sold transmission network operators in Germany. On the long run this development may touch the mass of distribution network operators legally unbundled in Europe. Consequently, one cannot assume that corporate capital structures will always be stable.

In research, three different modeling approaches have been used to analyze the effect of regulation on capital structures: ${ }^{1}$ First, classic trade-off theory provides insights how firms will set optimal levels of debt in the presence of competition. Second, several multi-stage bargaining models describing the link between investment, debt financing and tariff-setting have been developed. Third, regulatory climate models describe the impact of unfavorable regulation on capital structure of firms.

The starting point of trade-off-theory was the search for the adequate cost of capital for equity payments in order to get a better understanding of investment and financing decisions. Prior to Modigliani and Miller (1958), authors frequently concluded that the cost of equity will be equal to the interest rate on bonds. Modigliani and Miller (1958) state that a firm's market value is independent of its financing and of its dividend policy (Modigliani and Miller, 1961). In a review of their basic work, Modigliani and Miller (1963) introduced the tax shield of debt in the concept and concluded that firms should exclusively be financed with debt. Two relevant literature streams resulted at this point. The first analyzes the impact of regulation on the basic model, the second gathers insights regarding bankruptcy costs and detailed tax effects. The first stream followed an empirical test of the valuation theory by Miller and Modigliani (1966) in which they present the cost of capital of utilities firms. ${ }^{2}$ The results were thoroughly discussed in for instance Gordon (1967) and Elton and Gruber (1971, 1972). Jaffe and Mandelker (1976) present a more general model of valuation under regulation, which summarizes the state of discussion by including the other models as special cases in a general model. They conclude that under cost of service regulation, optimal leverage cannot be determined without knowledge about demand and supply curves.

As part of the second literature stream in trade-off-theory, Kraus and Litzenberger (1973) introduce bankruptcy costs that increase with leverage in their concept and consequently find that capital structure does actually matter. The trade-off-theory suggests a capital structure that optimizes between the tax shield and potential bankruptcy costs. Miller (1977) states that

\footnotetext{
${ }^{1}$ This paper will not consider pecking-order-theory by Myers (1984) as no analytical research links regulation and the pecking order. This theory of capital structure assumes that there is no optimal structure and that capital structure is opportunity driven. If one accepts pecking-order to be the only theory capable of explaining capital structure, then regulators can only influence capital structure by steering the companies' cashflows on a yearly basis.

${ }^{2}$ Utilities firms were often used in that kind of empirical research because large samples of firms were available, products, technology and markets were relatively homogeneous and earnings were stable.
} 
the impact of bankruptcy cost is overestimated. ${ }^{3}$ He points out that the tax saving is less than usually predicted, as personal taxes on bonds are regularly superior to personal taxes on dividends and capital gains. DeAngelo and Masulis (1980) discuss the existence of a non-debt tax shield which is due to for instance non-cash charges such as depreciations and investment tax credits. They find that the existence of this tax shield is sufficient to overturn the leverage irrelevancy stated by Miller (1977). Scott (1976) discusses the optimal capital structure in the context of a one-period equilibrium model. Bradley et al. (1984) present a theoretical model that synthesizes the different aspects of optimal capital structure. The static trade-off-theory of capital structure mainly represents the framework to discuss capital structure issues of regulated companies. Brennan and Schwartz (1984) make an additional step by modeling trade-off theory in a dynamic context. An exhaustive overview over capital structure theory is published in Harris and Raviv (1991).

Besides general trade-off-theory, some authors explicitly model the impact of regulation. Dasgupta and Nanda (1993) discuss a three-stage bargaining model of regulation. In the first stage, debt is issued. In the second stage, the regulator sets tariffs and in the third stage, the regulated firm receives payment for output and has to pay its costs. Spiegel (1994) presents a similar three-stage game model in which firms choose their capital structure and examine the effects on investment and regulated prices. The author finds that the use of a rate of return regime leads to higher debt, because the regulated firms threaten the regulator with bankruptcy, the regulator thus accepts higher prices. If regulators limit debt, they reduce incentives for investment which may lead to detrimental quality. Spiegel and Spulber (1994) find that the firm chooses its equity and debt in order to affect the outcome of the regulatory process. In equilibrium, the firm issues a positive amount of debt and the probability of bankruptcy is positive. They conclude that under given regulation, firms can increase the rate-of-return issuing more debt. What is common to all of these papers is the ex post setting of rate of returns and thus the conclusion that higher debt will lead to higher returns. If rates are set ex ante and are thus not firm specific, the results may be very different. In this context, the work of Fraja and Stones (2004) is of interest. The authors analyze whether there is a socially optimal capital structure for a regulated firm in a price cap regime. They find that increasing leverage may lead to lower tariffs due to the reduction of cost of capital until a given level, at which potential bankruptcy becomes costly. All this work signals that regulators should care for capital structure and indicates that the impact of debt on tariffs and on firm profits depend on the regulatory regime.

Rao and Moyer (1994) discuss the impact of regulatory climate on capital structure using a CAPM-based theoretical model. The stochastic terminal value of the regulated firm depends on its asset base and an expected after-tax return that is given by the weighted average cost of capital. The realized returns differ by a given factor from the expected returns, the difference capturing the uncertainty in returns due to regulatory quality. Their model predicts that regulated firms will react on the regulatory climate by adapting their capital structure. A less favorable regulatory climate will lead to a higher level of debt, the leverage being restricted by the costs of potential bankruptcy.

Empirical evidence with regard to capital structure mainly focuses on the impact of leverage and the risk effect. Robichek et al. (1973) identify a significant and positive correlation between leverage and the cost of equity for utilities firms. Taggert (1985) finds that the introduction of regulation between 1912 and 1922 in the US led to higher debt and attributes this to a reduction of risk. Chen and Fanara (1992) test hypothesis of trade-off theory and peckingorder theory based on 138 issues of debt, common stock and preferred stock between 1976 and 1982 with regards to 96 US electric utilities. They find that the adjustment of capital structure is mainly driven by agency problems (which they measure by the number of directors and) speaking in favor of pecking-order. Meanwhile, the long-term target capital structure is significantly determined by bankruptcy costs, non-debt tax shields and regulatory stringen-

\footnotetext{
${ }^{3}$ Baxter (1967), Warner (1977), Altman (1984) and Weiss (1990) have conducted empirical research analyzing bankruptcy costs. Baxter (1967) states that, with regard to personal bankruptcies, about $20 \%$ of realizations are administrative costs. Warner (1977) presents evidence that the direct bankruptcy costs (such as legal, accounting, filing and other administrative costs) of railroad companies average $2.8 \%$ of market value. Altman (1984) states that total bankruptcy cost amount to $16.7 \%$ of market value in the year of bankruptcy. Roughly $2 / 3$ of bankruptcy costs are indirect, measured by loss of sales. Weiss (1990) finds that direct average costs of bankruptcy amount to $3.1 \%$ of book value of debt plus market value of equity.
} 
cy. The results imply that these factors have a more long-term effect. Sanyal and Bulan (2005) find by a comparison of US and UK electric utilities that regulatory risk (e.g. uncertainty about the new market structure, attitude of the regulation authority) and market risk (e.g. new competitors) lead to a reduction of leverage. Bortolotti et al. (2008) present evidence that leverage increases if firms are privately controlled and if they are controlled by an independent regulatory agency. They further present evidence that privately controlled firms with high leverage receive higher prices. Leverage is thus used as a strategic lever to prevent the regulator to cut prices after investments are made by threatening him with bankruptcy, an argument already presented in Spiegel (1994).

The presented research, theoretical and empirical, does not address important issues relevant for recent approaches of capital structure regulation. First, in many regulation regimes the regulator is confronted with a high number of firms. Thus from a yardstick regulation perspective efficient rather than individual costs of capital are remunerated. Second, several regulatory regimes are characterized by regulatory periods, in which no modification of regulatory parameters is planned. The evidence discussed up to this point mostly assumes a regulatory action after the agent's action. Third, other explanation for debt such as stochasticity of cash-flows or tangibility of assets exist that may explain different degrees of leverage on an industry level.

To provide another perspective on the regulation of capital structures, this paper adapts concepts from trade-off-theory to model corporate control decisions, analyzing the impact of regulatory incentives, bankruptcy costs and tax regimes. Different concepts/regimes of capital structure regulation under uncertainty are distinguished and analyzed. A set of different parameterizations of the models will be used in order to discuss the impact of capital structure regulation on optimal leverage, especially in the presence of impacts stemming from tax shields and bankruptcy costs. The structure of this paper is as follows: In the second section, the analytical model is introduced. The third section discusses characteristics of optimal capital structure and presents comparative statics. In the fourth section, empirical facts about network operators and regulatory regimes with regards to optimal capital structure will be summarized. The impact of different parameters on the optimal leverage is discussed based on numerical simulations in section five. This section shall answer the question if approaches to capital structure regulation provide significant incentives. The last section concludes and indicates areas for potential future research work.

\section{Model - Trade-off-theory}

This section discusses an analytical model of optimal capital structure under different types of regulation. First, the basic model will be presented. Second, regulation will be included in the model. Third, comparative statics will be discussed.

\subsection{The basic model}

The model presented is based on a one-period model comparable to Scott (1976) and Bradley et al. (1984). Classically, regulators accept required equity return as a financial charge that has to be financed by the network customers only up to a certain limit to give incentives for leverage. ${ }^{4}$ This model is based on the assumption that the regulator will attribute some capital cost ex post to the network operator, which can be incorporated in network tariffs in the next period.

\footnotetext{
${ }^{4}$ This classic approach is in contrast to a yardstick approach. In a pure yardstick regulation model, even asset value would be of no importance for the regulated tariffs.

${ }^{5}$ A difference between regulatory regimes is the treatment of Working Capital. In the UK approach, capital return is attributed for asset value, in the German approach for asset value minus subsidies plus Working Capital. A second major differentiation is if the regulated asset base or the regulated return accounts for inflation. While the OFGEM attributes a real weighted average cost of capital (WACC) to the asset base which is indexed with inflation, many other regulators keep the asset base stable and account for inflation via a nominal WACC.
} 
The basic structure of this model is as follows: At the beginning of the period, the firm finances the regulatory asset value $V^{R}$ by choosing the equity ratio $q$ depending on the book value of equity $E$ and debt $D$. Book values are used because they are very important for regulation authorities, as only a minor number of regulated firms are listed in stock exchanges. Consequently, most regulators build calculation schemes solely based on book values.

$$
q=\frac{E}{V^{R}}=\frac{E}{E+D}
$$

After one period, earnings before interest and taxes, denoted $x$, are realized based on the probability density function $f(x)$ following a linear production function. Due to the assumption of an ex-ante regulation, they are random from the perspective of the regulated firm:

$$
x=a \cdot g\left(E, D, o, r_{e}, r_{d}, m\right)
$$

Besides the level of equity and debt, the operational expenditures $o$, the regulated return on equity $r_{e}$, the regulated return on debt $r_{d}$ and the OPEX-margin attributed by the regulator $m$ are relevant to compute $x$. In the case of a pure rate-of return regulation with only one rate of return on cost, $r_{e}=r_{d}=m$. The term $a$ models uncertainty of planned EBIT and is characterized by its expectation and standard deviation. Its expectation $E[a]$ depends on external, regulation-induced factors (benchmarking procedure, cost of the shadow firm) and internal factors (process efficiency, expectation of possible cost reductions). The standard deviation describes the uncertainty in reaching the expected EBIT-targets. It depends for instance on possible sales quantity variations due to fluctuations in temperature (measured for instance by heating degree days) or the share of unplanned repairs in total maintenance expenses. If assets are remunerated based on a benchmark equity ratio $q^{R}$, then $x$ is given by:

$$
\begin{aligned}
& x^{B M}=a \cdot\left\lfloor\left(q^{R} r_{e}+\left(1-q^{R}\right) r_{d}\right) V^{R}+m \cdot o\right\rfloor \\
& =a \cdot\left(r_{v} V^{R}+m \cdot o\right)
\end{aligned}
$$

In this case, revenues are independent of the equity ratio chosen. Technically, price and revenue caps may both be used to achieve this result. The term $r_{v}$ represents the weight average cost of capital that the regulator assumes for network operations. It comprises a predefined level of equity $q^{R}, r_{e}$ that is usually computed based on capital asset pricing model considerations and $r_{d}$. If the regulator takes the individual capital structure into account, then:

$$
x^{I N D}=a \cdot\left\lfloor q r_{e} V^{R}+(1-q) r_{d} V^{R}+m \cdot o\right\rfloor
$$

A third possibility is the introduction of a cap. The German regulator Bundesnetzagentur introduced an equity ratio cap of $40 \%$ in 2007 . If the equity ratio is inferior to the regulatory maximum equity ratio, then individual capital structure is considered. If it is above, then the regulatory value represents a cap.

$$
x^{C A P}=a \cdot \begin{cases}q r_{e} V^{R}+(1-q) r_{d} V^{R}+m \cdot o, & \text { if } q<q^{R} \\ r_{v} V^{R}+m \cdot o, & \text { if } q \geq q^{R}\end{cases}
$$

If one assumes ex-post cost plus regulation with individual capital structure, then:

$$
x^{E P_{-} I N D}=q r_{e} V^{R}+(1-q) r_{d} V^{R}+m \cdot o
$$

In this case, bankruptcy is not possible because the regulation scheme will permit the firm to realize a predefined profit, even in a hazardous environment. The introduction of a CAP in an ex-post setting (EP_CAP) is possible, being analogue to (5). A last option that will be included in this paper is the case of ex-post regulation with benchmark capital structure.

$$
x^{E P_{-} B M}=r_{v} V^{R}+m \cdot o
$$

In all cases where bankruptcy is possible, if the end-of-period earnings minus interest on debt are sufficiently negative to consume all equity, then equity becomes worthless and the firm is liquidated. The condition is: 


$$
\begin{aligned}
& x-r_{d} D+E<0 \\
& \Leftrightarrow x<(1-q) r_{d} V^{R}-q V^{R} \\
& \Leftrightarrow x<-q V^{R}\left(1+r_{d}\right)+r_{d} V^{R}
\end{aligned}
$$

The limit of $x$, at which the firm will go into bankruptcy, is denoted $b$.

$$
b_{q}=-q V^{R}\left(1+r_{d}\right)+r_{d} V^{R}
$$

Before presenting the model structure, some assumptions about the tax concept are required. Corporate benefits are taxed with the corporate tax rate $t_{c}$, income from dividends and capital gains with the personal taxes on stocks $t_{p s}$ and income from interest payments with the personal taxes on bonds $t_{p b}$. The difference between what remains after the taxation on bonds (1 $\left.t_{p b}\right)$ and the taxation on stocks $\left(1-t_{c}\right)\left(1-t_{p s}\right)$ is denominated 'tax shield'. In the case of bankruptcy, bondholders will pay no tax.

Considering bankruptcy costs being a constant fraction $k$ of regulated asset base $V$, the end-ofperiod post-tax-payments to the stakeholders in the case of bankruptcy are given by:

$$
\int_{-\infty}^{b_{q}}(1-k) V^{R} f(x) d x
$$

In this case, debt holders liquidate the firm. If the firm does not go into bankruptcy, then the bondholders receive the face value of debt plus an interest payment:

$$
\begin{aligned}
& (1-q) V^{R} \int_{b_{q}}^{\infty} f(x) d x+(1-q)\left(1-t_{p b}\right) r_{d} V^{R} \int_{b_{q}}^{\infty} f(x) d x \\
& =V^{R}\left[1-F\left(b_{q}\right)\right](1-q)\left[1+\left(1-t_{p b}\right) r_{d}\right]
\end{aligned}
$$

The end-of period-value to the shareholders is given by:

$$
\begin{aligned}
& \int_{b_{q}}^{\infty} q V^{R} f(x) d x \\
& +\left(1-t_{p s}\right)\left(1-t_{c}\right)\left[\int_{b_{q}}^{\infty} x f(x) d x-\left((1-q) r_{d} V^{R}\right) \int_{b_{q}}^{\infty} f(x) d x\right]
\end{aligned}
$$

From a tax perspective, one has to differentiate if carrying forward losses (in the case of $x<0$ ) is possible (leading to a negative tax payment) or not. In our model, it is possible to carry negative taxes forward. Given a different assumption, taxes would only have to be considered for $x>0$. Interest on debt has to be paid until bankruptcy, regardless if earnings are positive or negative. The total market value of the firm at the beginning of the period $V$, that is subject to optimization through the manager amounts to the discounted sum of the presented elements. The discount factor $r_{0}$ is risk-free.

\footnotetext{
${ }^{6}$ This represents a minor simplification: if insolvency occurs and some return on debt inferior to $r_{d}$ is paid, than some tax payment would result. As this represents a rare case and the effect would only be minor, it is not considered.

${ }^{7}$ At a first glance, this may appear to contrast the concept of shareholder value. In Spiegel (1994) for instance, solely the value to equity holders is modeled. The difference between both approaches lies within the potential bankruptcy case. In Spiegel (1994), debt repayment is assumed certain. In this case, no default risk premium is required for debt. In this paper, the consideration of the bankruptcy case is analogue to modeling debt risk premium. In the real world, the interest rate on debt is linked to leverage. This is consistent with the model of Dasgupta and Nanda (1993, p. 481) in which debt is sold at a fair price leading to the managerial decision of optimizing total firm value.
} 


$$
\begin{aligned}
V=\frac{1}{r_{0}}\left[\int_{-\infty}^{b_{q}}(1-k) V^{R} f(x) d x\right. \\
+\left[\left(1-t_{p b}\right)-\left(1-t_{p s}\right)\left(1-t_{c}\right)\right] \int_{b_{q}}^{\infty}(1-q) r_{d} V^{R} f(x) d x \\
+\left(1-t_{p s}\right)\left(1-t_{c}\right) \int_{b_{q}}^{\infty} x f(x) d x \\
\left.\quad+\int_{b_{q}}^{\infty} V^{R} f(x) d x\right]
\end{aligned}
$$

The first line represents the value in case of bankruptcy, the fourth the value if no bankruptcy occurs. The second line incorporates the tax shield of debt; the third line captures the earning stream.

\section{Characteristics of Optimal Capital Structure}

\subsection{Optimality condition}

In the benchmarking case, the network operator revenues $x$ are independent of the capital structure decision. The first derivative of its market value is given by:

$$
\begin{aligned}
& \frac{\partial V^{B M}}{\partial q}=\frac{1}{r_{0}}\left[-f\left(b_{q}\right) \cdot\left(-V^{R}\left(1+r_{d}\right)\right) \cdot k V^{R}\right. \\
& \quad+\left[\left(1-t_{p b}\right)-\left(1-t_{p s}\right)\left(1-t_{c}\right)\right] r_{d} V^{R}\left[-1+F\left(b_{q}\right)-(1-q) f\left(b_{q}\right)\left(-V^{R}\left(1+r_{d}\right)\right)\right] \\
& \left.\quad-\left(1-t_{p s}\right)\left(1-t_{c}\right) b_{q} \cdot f\left(b_{q}\right) \cdot\left(-V^{R}\left(1+r_{d}\right)\right)\right]
\end{aligned}
$$

We expect the tax shield to have less impact than in classical trade-off-theory models. First, an additional regulatory impact is modeled. Second, the tax is income-based while some authors use wealth tax concepts such as Bradley et al. (1984) leading to an overestimation of the tax shield-effect. Third, while bankruptcy puts invested equity plus current earnings in stake, the tax shield is only applicable to earnings.

Proposition 1: In the case of a benchmark capital structure, the trade-off between tax shield and bankruptcy costs leads to the existence of an inner solution for the optimal capital structure.

Proof of proposition 1: Using Bolzano's theorem one can formally prove that one inner solution exists if the two following (sufficient) conditions are fulfilled: ${ }^{8}$

$$
k>\left(1-t_{p s}\right)\left(1-t_{c}\right)\left(q\left(1+r_{d}\right)-r_{d}\right)
$$

This signifies that it is easier to prove formally the existence of one optimal solution in the case of higher bankruptcy costs, higher tax shields and higher return on debts. This is intuitive as these three factors determine the magnitude of the trade-off between tax shield and the costs of a potential bankruptcy. The second condition

$$
F\left(b_{q} \mid q=0\right) \geq 0.5
$$

\footnotetext{
${ }^{8}$ Cf. Appendix A
} 
means that a bankruptcy probability of $50 \%$ in the case of pure debt-financing is required to prove formally the existence of one inner optimum. Sensitivity analysis will show that inner optimums are typical in the case of $B M$.

In the case of $I N D$, the regulator considers individual capital structures and then the first derivative of the market value of the firm is given by:

$$
\begin{aligned}
& \frac{\partial V^{I N D}}{\partial q}=\frac{1}{r_{0}}\left[-f\left(b_{q}\right) \cdot\left(-V^{R}\left(1+r_{d}\right)\right) \cdot k V^{R}\right. \\
& \quad+\left[\left(1-t_{p b}\right)-\left(1-t_{p s}\right)\left(1-t_{c}\right)\right] r_{d} V^{R}\left[-1+F\left(b_{q}\right)-(1-q) f\left(b_{q}\right)\left(-V^{R}\left(1+r_{d}\right)\right)\right] \\
& \left.\quad+\left(1-t_{p s}\right)\left(1-t_{c}\right)\left[\left(1-F\left(b_{q}\right)\right) a\left(r_{e}-r_{d}\right) V^{R}-b_{q} \cdot f\left(b_{q}\right) \cdot\left(-V^{R}\left(1+r_{d}\right)\right)\right]\right]
\end{aligned}
$$

Proposition 2: If the regulator considers individual capital structure, then the regulated firm will increase equity ratio beyond the optimal level determined in the benchmark case.

Proof of proposition 2: From (14) and (17), one can see that $\partial V^{I N D} / \partial q>\partial V^{B M} / \partial q$ if $r_{e}>r_{d,}$, the difference prevailing from the first term in the third line of (16) which corresponds to:

$$
\frac{\partial V^{I N D}}{\partial q}-\frac{\partial V^{B M}}{\partial q}=\frac{1}{r_{0}}\left[\left(1-t_{p s}\right)\left(1-t_{c}\right)\left[\left(1-F\left(b_{q}\right)\right) a\left(r_{e}-r_{d}\right) V^{R}\right]\right.
$$

Assuming negative monotonicity of $\partial V^{B M} / \partial q$, this signifies that due to additional regulatory returns on equity, a regulated firm will reduce leverage if its individual capital structure is considered. Due to the first term, it is now even possible that the first derivative does not become negative and that an inner optimum does not exist.

In the case of $C A P$, the partial derivative of $V$ with regards to $q$ corresponds to the case of $I N D$ up to the predefined target ratio $q_{r}$.

$$
\frac{\partial V^{C A P}}{\partial q}= \begin{cases}\partial V^{I N D} / \partial q, & \text { if } q<q^{R} \\ \partial V^{B M} / \partial q, & \text { if } q \geq q^{R}\end{cases}
$$

Proposition 3: If the case of ex post regulation, the absence of bankruptcy risk leads to pure bang-bang-strategies.

Proof of proposition 3: In the case of ex post regulation, bankruptcy is not possible and thus $f\left(b_{q}\right)=0$ and $F\left(b_{q}\right)=0$. If the individual capital structure is considered, then the first derivatives are given by:

$$
\begin{aligned}
& \frac{\partial V^{E P_{-} I N D}}{\partial q}=\frac{1}{r_{0}}\left[-\left[\left(1-t_{p b}\right)-\left(1-t_{p s}\right)\left(1-t_{c}\right)\right] r_{d} V^{R}+\left(1-t_{p s}\right)\left(1-t_{c}\right)\left(r_{e}-r_{d}\right) V^{R}\right] \\
& \frac{\partial V^{E P_{-} B M}}{\partial q}=\frac{1}{r_{0}}\left[-\left[\left(1-t_{p b}\right)-\left(1-t_{p s}\right)\left(1-t_{c}\right)\right] r_{d} V^{R}\right]<0
\end{aligned}
$$

In the case of $E P \_I N D$, capital structure does not matter if $\left(1-t_{p b}\right) r_{d}=\left(1-t_{p s}\right)\left(1-t_{c}\right) r_{e}$. In any other case, the exclusion of risk leads to a bang-bang-strategy solely financing by equity (if post-tax return on equity is superior) or debt (in the opposite case). ${ }^{9}$ The last case $E P \_B M$ leads to a pure debt strategy due to the existence of a tax shield.

Figure 2 shows exemplarily the different cases of $\partial V / \partial q$. On the left side, tax shield dominates additional equity returns. On the right side, tax shields are less important.

\footnotetext{
${ }^{9}$ This may appear unrealistic at a first glance as it represents an extreme scenario due to the fact that bankruptcy is excluded in this case. However, the results are in line with what one may expect from any classic trade-offtheory-model.
} 

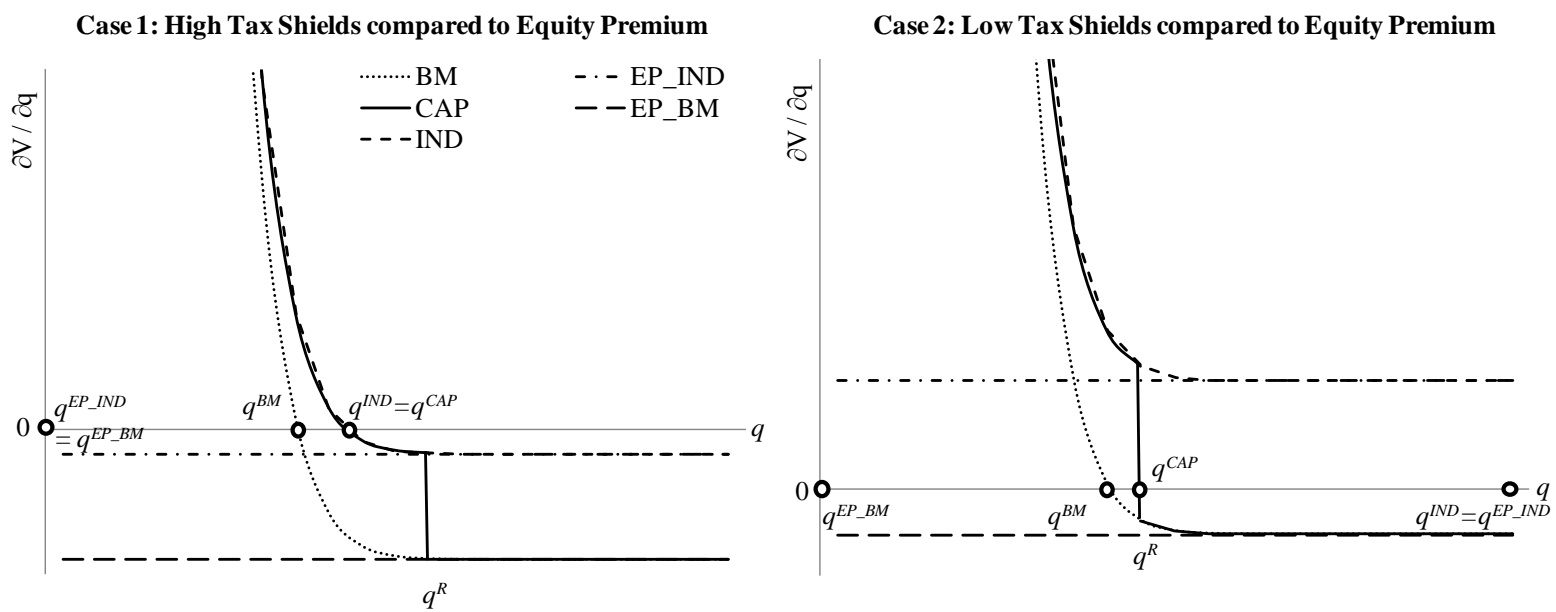

Figure 1: Partial derivatives of the value function with respect to $q$ - exemplary figure

If revenues are set exogenously and bankruptcy is possible (case $B M$ ), then an inner optimum can be expected in both cases. Important tax shields given, IND and $C A P$ will see inner solutions as well. Without a cap for the individual model and given lower tax shields (on the right side), equity ratio will be maximized. In the partial derivative for the cap case, a downward jump occurs at $q=q^{R}$. If a cap is fixed by regulation authorities, then firms will choose an equity ratio close to the cap because otherwise they would lose tax shield effects. Ex post regulation approaches in our model always lead to pure debt or equity strategies. An EP_BM model leads to solely financing with debt, as this maximizes the tax shield. In the case of $E P \_I N D$, the result depends mostly on whether the tax shield dominates equity premium.

\subsection{Comparative statics}

In this section, impact of bankruptcy cost, taxes, and attributed rates of return will be discussed. The impact of rates of return on equity and debt is more complicated to discuss: They have a direct impact on the optimality condition via the tax shield and attributed revenues and an indirect impact by altering the probability of bankruptcy. Thus after discussing the direct impact, a consideration on the change of bankruptcy risk is required before considering the total impact.

\section{Bankruptcy costs}

First, the impact of bankruptcy costs is analyzed:

$$
\frac{\partial}{\partial k}\left(\frac{\partial V^{B M}}{\partial q}\right)=\frac{\partial}{\partial k}\left(\frac{\partial V^{I N D}}{\partial q}\right)=-\frac{1}{r_{0}} f\left(b_{q}\right) \cdot b_{q}{ }^{\prime} \cdot V^{R}>0
$$

An increase of bankruptcy costs will push the partial derivative upwards thus increasing the equity ratio and decreasing leverage. As this effect is found to be limited to the case of exante regulation, the results oppose Spiegel (1994) and Spiegel and Spulber (1994). In both articles, higher bankruptcy costs lead to more debt due to the regulation authority accepting higher prices. In the case of an ex post-regime, bankruptcy in our model is not possible and thus, $k$ has no impact on capital structure. In Spiegel (1994), the possibility of a bankruptcy is positive in equilibrium. The differences are due to the fact that in this model, additional bankruptcy costs are directly borne by customers not permitting additional benefits to the regulated firm.

\section{Taxes on bonds}

Taxes comprise personal taxes on bonds, personal taxes on stock benefits and dividends and taxes on corporate benefits. First, personal taxes on bonds are discussed: 


$$
\begin{aligned}
& \frac{\partial}{\partial t_{p b}}\left(\frac{\partial V^{B M}}{\partial q}\right)=\frac{\partial}{\partial t_{p b}}\left(\frac{\partial V^{I N D}}{\partial q}\right)=\frac{r_{d} V^{R}}{r_{0}}\left[1-F\left(b_{q}\right)-(1-q) f\left(b_{q}\right) b_{q}^{\prime}\right]>0 \\
& \frac{\partial}{\partial t_{p b}}\left(\frac{\partial V^{E P_{-} I N D}}{\partial q}\right)=\frac{\partial}{\partial t_{p b}}\left(\frac{\partial V^{E P_{-} B M}}{\partial q}\right)=\frac{r_{d} V^{R}}{r_{0}}>0
\end{aligned}
$$

An increase of personal taxes on bonds reduces the tax shield and thus shifts the optimality condition upwards reducing leverage. This effect is consistent with Bradley et al. (1984). This effect is more important in the ex post regime because the tax shield will never be lost due to bankruptcy.

\section{Taxes on corporate profits and dividend income}

$$
\begin{aligned}
& 0>\frac{\partial}{\partial t_{c}}\left(\frac{\partial V^{B M}}{\partial q}\right)=\frac{1-t_{p s}}{r_{0}}\left[r_{d} V^{R}\left(-1+F\left(b_{q}\right)+(1-q) f\left(b_{q}\right) b_{q}^{\prime}\right)+b_{q} \cdot f\left(b_{q}\right) \cdot b_{q}^{\prime}\right] \\
& >\frac{\partial}{\partial t_{c}}\left(\frac{\partial V^{I N D}}{\partial q}\right)=\frac{1-t_{p s}}{r_{0}}\left[\begin{array}{l}
r_{d} V^{R}\left(-1+F\left(b_{q}\right)+(1-q) f\left(b_{q}\right) b_{q}^{\prime}\right)+b_{q} \cdot f\left(b_{q}\right) \cdot b_{q}^{\prime} \\
-\left(1-F\left(b_{q}\right)\right) a\left(r_{e}-r_{d}\right) V^{R}
\end{array}\right] \\
& \text { and } \quad 0>\frac{\partial}{\partial t_{c}}\left(\frac{\partial V^{E P_{-} B M}}{\partial q}\right)=-\frac{1-t_{p s}}{r_{0}} r_{d} V^{R} \\
& >\frac{\partial}{\partial t_{c}}\left(\frac{\partial V^{E P_{-} I N D}}{\partial q}\right)=\frac{1-t_{p s}}{r_{0}}\left[-r_{d} V^{R}-\left(r_{e}-r_{d}\right) V^{R}\right]
\end{aligned}
$$

An increase of taxes on corporate profits $t_{c}$ or dividend income $t_{p s}$ has two effects: It raises the tax shield (increasing leverage) and increases the negative debt payment in the case of bankruptcy (decreasing leverage). Consequently, the impact depends on the level of $q$. In this case, in (23) $t_{p s}$ is replaced by $t_{c}$ in the numerator outside the brackets, all other things being equal.

\section{Bankruptcy risk}

One naturally expects that an increase of bankruptcy risk leads to less debt in equilibrium. However, Scott (1976), Castanias (1983) and Bradley et al. (1984) obtain ambiguous results regarding the link between the standard deviation and the level of debt. These authors use numerical simulations finding that an increase of risk reduces the optimal level of debt for lower levels of risk. Only in the case of very high values of standard deviation, this effect may be reversed. In our model, two possibilities exist to alter the risk of bankruptcy. The first consists of altering $E[a]$, the second consists of modifying the variance $\operatorname{Var}[a]$. In a regulatory context, the first case may be given if the regulator increases pressure on regulated firms by for instance significantly raising the X-factor. The risk of bankruptcy increases, because for a given level of $b_{q}$ its probability is increased. The second case may arise, if the benchmarking peer group is altered by the regulation authority.

A decrease of $E[a]$ raises bankruptcy probability $F\left(b_{q}\right)$ as lower expected revenues are attributed. Consequently $f\left(b_{q}\right)$ and $F\left(b_{q}\right)$ increase (in the case of a normal distribution) while $b_{q}$ remains unchanged. Graphically, this could be represented by moving a normal distribution to the right. One can show that if the following condition is met, than $\partial V^{B M} / \partial q$ decreases in $E[a]$. This means that lower risk will lead to more leverage.

$$
k-\left\lfloor\left(1-t_{p b}\right) r_{d}(1-q)\right\rfloor-q\left(1-t_{p s}\right)\left(1-t_{c}\right)>0
$$

If this sufficient restriction is given, then more expected revenues lead to more debt ${ }^{10}$ With regard to $\partial V^{I N D} / \partial q$, this effect is even stronger signifying that the gap between $\partial V^{B M} / \partial q$ and $\partial V^{I N D} / \partial q$ widens with additional risk. This is due to a tax modeling aspect: In the case of

\footnotetext{
${ }^{10}$ This restriction appears relatively severe, but is loosened up by an additional term which cannot be included in this restriction for analytical reasons. Calculations in the next section will show that $\partial V^{B M} / \partial q$ increases in $E[a]$.
} 
bankruptcy, taxes on benefits are not imposed. The tax advantage in $\partial V^{I N D} / \partial q$ consequently increases in bankruptcy risk. This effect is expected to be minor. In $\partial V^{E P \_B M} / \partial q$ or $\partial V^{E P} I N D / \partial q$, no effect will occur because bankruptcy is impossible.

The second channel to alter the risk structure consists of increasing the variance of the probability distribution. Assuming a normal distribution, an increase of standard deviation will result in a decrease of $f\left(b_{q}\right)$ and an increase of $F\left(b_{q}\right)$ making the probability distribution flatter. The problems described in e.g. Scott (1976) or Bradley et al. (1984) reappear in this model, as no clear analytical relationship between the standard deviation and the optimality condition can be derived. We expect $\partial V^{B M} / \partial q$ to increase with $\sigma$, thus reducing leverage under increased risk and that the gap between $\partial V^{B M} / \partial q$ and $\partial V^{I N D} / \partial q$ widens with higher $\sigma$. Simulations were used to gain insights about this relationship.

\section{Attributed return on debt and equity}

First, the direct impacts of the rates are evaluated.

$$
\frac{\partial}{\partial r_{d}}\left(\frac{\partial V^{E P_{-} I N D}}{\partial q}\right)=\frac{\partial}{\partial r_{d}}\left(\frac{\partial V^{E P_{-} B M}}{\partial q}\right)<\frac{\partial}{\partial r_{d}}\left(\frac{\partial V^{I N D}}{\partial q}\right)<\frac{\partial}{\partial r_{d}}\left(\frac{\partial V^{B M}}{\partial q}\right)<0
$$

An increase of return on debt increases the value of tax shields and leads to more leverage. To understand this impact, one has to bear in mind that the agent increases total value for shareholders and debt holders. With regards to the case of IND, this effect is slightly reinforced due to an additional tax shield in case of bankruptcy. In the case of ex-post regulation, bankruptcy is excluded and thus, the tax shield is more important. A second direct impact of an increase of $r_{d}$ is the decrease of equity premium, leading to a decrease of $\partial V / \partial q$ in IND and EP_IND and thus more debt.

$$
\frac{\partial}{\partial r_{e}}\left(\frac{\partial V^{B M}}{\partial q}\right)=0=\frac{\partial}{\partial r_{e}}\left(\frac{\partial V^{E P_{-} B M}}{\partial q}\right)<\frac{\partial}{\partial r_{e}}\left(\frac{\partial V^{I N D}}{\partial q}\right)<\frac{\partial}{\partial r_{e}}\left(\frac{\partial V^{E P_{-} I N D}}{\partial q}\right)
$$

In the $B M$-case, optimal capital structure does not directly depend on the granted return on equity. In the case of $I N D$ and $E P$ where individual capital structure is considered, an increase of $r_{e}$ leads to an upward movement of $\partial V / \partial q$ and thus to more equity. With the knowledge of these direct effects and the results of the bankruptcy risk section, one can now reevaluate the total impact of $r_{e}$ and $r_{d}$ on leverage.

\begin{tabular}{|c|c|c|c|c|c|c|c|c|}
\hline \multirow[b]{2}{*}{ Model } & \multicolumn{3}{|c|}{$\partial(\partial V / \partial q) / \partial r_{d}$} & \multirow[b]{2}{*}{ Bankruptcy $b_{q}$} & \multirow[b]{2}{*}{ Total } & \multicolumn{2}{|c|}{$\partial(\partial V / \partial q) / \partial r_{e}$} & \multirow[b]{2}{*}{ Total } \\
\hline & Tax shield & Revenue & $f\left(\boldsymbol{b}_{q}\right) / \boldsymbol{F}\left(\boldsymbol{b}_{q}\right)$ & & & Revenue & $f\left(\boldsymbol{b}_{q}\right) / \boldsymbol{F}\left(\boldsymbol{b}_{q}\right)$ & \\
\hline$B M$ & $<0$ & $=0$ & $<0$ & $>0$ & $?$ & $=0$ & $<0$ & $<0$ \\
\hline$I N D$ & $<0$ & $<0$ & $<0$ & $>0$ & $?$ & $>0$ & $<0$ & $>0$ \\
\hline$E P \_I N D$ & $<0$ & $<0$ & $=0$ & $=0$ & $<0$ & $>0$ & $=0$ & $>0$ \\
\hline$E P \_B M$ & $<0$ & $=0$ & $=0$ & $=0$ & $<0$ & $=0$ & $=0$ & $=0$ \\
\hline
\end{tabular}

Table 1: Impact of rates on return on optimality condition

Explanation of effects: Tax shield represents $\left(1-t_{p s}\right)-\left(1-t_{p s}\right)\left(1-t_{c}\right)$. 'Revenues' means an additional direct impact in revenues due to an increase of interest. $f\left(b_{q}\right) / F\left(b_{q}\right)$ signifies an effect due to an total increase of expectation and thus a reduction of bankruptcy risk. Bankruptcy $b_{q}$ signifies an increase of the given value due to higher return on debt.

An increase of the return on debt may lead to more leverage for three reasons: First, increase of tax shield; second, a direct increase of revenue; third, a reduction of bankruptcy risk. On the other hand, it increases bankruptcy risk via $b_{q}$ reducing incentives for leverage. The total effect is thus not evident. As for the return on equity, in the case of $B M$, an increase leads to more leverage solely due to a decrease of risk. In the case of IND and $B M$ the results are ambiguous, but one expects the direct effect to dominate the indirect. Simulations in a following chapter will provide more insights. 


\section{Empirical Facts about Network Operators' Capital Structure}

Trade-off-theory models are difficult to validate empirically if the focus lies on one industry only, Bradley et al. (1984) for instance use a cross-industry test of his model. The aim of this section is another: Give an indication, what capital structures are observable and which regulatory models are common. Table 2 presents a sample of stock listed network operators, giving information about company size and the ratio of book equity to total equity and debt.

Table 2: Network operators (without significant other activities)

\begin{tabular}{|c|c|c|c|c|c|}
\hline Company & Country & Activity & $\begin{array}{c}\text { Network size } \\
\text { thds. } k m\end{array}$ & $\begin{array}{c}\text { Total equity \& debt } \\
b n . €\end{array}$ & 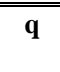 \\
\hline Transener & Argentina & ET, ED & 14 & 2.0 & 0.52 \\
\hline APA Group & Australia & GT, GD & 36 & 5.1 & 0.21 \\
\hline DUET Group & Australia & $\mathrm{ET}, \mathrm{ED}, \mathrm{GT}, \mathrm{GD}$ & 97 & 8.3 & 0.15 \\
\hline Envestra & Australia & GT, GD & 22 & 2.8 & 0.19 \\
\hline Spark Infrastructure & Australia & $\mathrm{ED}$ & 174 & 2.3 & 0.33 \\
\hline SP AusNet & Australia & ET, ED, GD & 62 & 8.2 & 0.06 \\
\hline Elia & Belgium & ET & 8 & 4.9 & 0.32 \\
\hline Snam Rete Gas & Italy & GT, GD & 82 & 16.7 & 0.31 \\
\hline Terna & Italy & ET & 62 & 9.8 & 0.25 \\
\hline Enagas & Spain & GT & 9 & 5.8 & 0.28 \\
\hline Red Electrica & Spain & ET & 35 & 6.8 & 0.22 \\
\hline National Grid & UK & ET, ED, GT, GD & 343 & 44.8 & 0.13 \\
\hline AGL Resources & US & GT, GD & 74 & 7.1 & 0.25 \\
\hline Atmos Energy & US & GT, GD & 123 & 6.5 & 0.33 \\
\hline ITC Holding & US & ET & 24 & 4.0 & 0.25 \\
\hline Kinder Morgen Energy P. & US & GT & 59 & 20.0 & 0.33 \\
\hline New Jersey Resources & US & GT, GD & 22 & 2.5 & 0.29 \\
\hline Nicor Inc & US & GD & 54 & 4.6 & 0.23 \\
\hline Northwest Natural Gas & US & GT, GD & 22 & 2.5 & 0.27 \\
\hline Piedmont Natural Gas & US & GT, GD & 49 & 3.1 & 0.30 \\
\hline TC Pipelines & US & GT, GD & 6 & 1.7 & 0.62 \\
\hline WGL Holding Inc & US & GT, GD & 42 & 3.4 & 0.33 \\
\hline
\end{tabular}

The abbreviation for the main business activities is as follows: ' $G$ ' stands for gas, ' $E$ ' for electricity, 'D' for distribution and ' $T$ ' for transportation. The company data was gathered in June 2010/2011. Network sizes were gathered on the companies' websites, financial data are 3year-averages taken from Reuters.

One can see that, across different countries and thus across regulatory models, a relatively high leverage is common. The mean of $q$ is 0.27 , its standard deviation 0.10 . Table 3 Fehler! Verweisquelle konnte nicht gefunden werden.gives an indication about the regulatory models used in practice and attributed predefined regulatory equity ratios.

Table 3: Approaches to capital structure regulation (electricity distribution)

\begin{tabular}{llllll}
\hline \hline Country & Regulator & Period & Model & Nominal/real & Equity ratio \\
\hline \hline Australia & Au. Energy Regulator & $2009-2014$ & $B M$ & Nominal Vanilla WACC & 0.40 \\
Austria & E-Control & $2010-2013$ & $B M$ & Nominal pre-tax WACC & 0.40 \\
Belgium & CREG & $2009-2012$ & $E P \_C A P$ & Nominal post-tax $r_{e}$, with cap & Cap: 0.33 \\
Czech Rep. & ERU & $2010-2014$ & $B M$ & Nominal pre-tax WACC & 0.60 \\
Estonia & ECA & 2010 & $B M$ & Nominal post-tax WACC & 0.50 \\
Finland & EMVI & $2008-2011$ & $B M$ & Nominal post-tax WACC & 0.70 \\
France & CRE & $2010-2012$ & $B M$ & Nominal pre-tax WACC & 0.40 \\
Germany & Bundesnetzagentur & $2009-2013$ & $C A P$ & Nominal pre-tax $r_{e}$, with cap & Cap: 0.40 \\
Hungary & Hungary Energy Office & $2009-2012$ & $B M$ & Real pre-tax WACC & 0.55
\end{tabular}




\begin{tabular}{llllll} 
Ireland & CER & $2006-2010$ & $B M$ & Real pre-tax WACC & 0.50 \\
Italy & AEEG & $2008-2011$ & $B M$ & Nominal pre-tax WACC & 0.50 \\
Kosovo & Energy Regulatory Office & $2006-2010$ & $B M$ & Real pre-tax WACC & 0.40 \\
Luxembourg & ILR & 2009 & $B M$ & Nominal pre-tax WACC & 0.40 \\
Netherlands & Neth. Comp. Authority & $2007-2009$ & $B M$ & Real pre-tax WACC & 0.40 \\
New Zealand & Commerce Commission & $2009-2013$ & $B M$ & Nominal post-tax WACC & 0.40 \\
Norway & NVE & $2007-2011$ & $B M$ & Nominal pre-tax WACC & 0.40 \\
Romania & ANRE & $2005-$ & $I N D$ & Real post-tax WACC & - \\
Spain & CNE & $2009-$ & $B M$ & Nominal post-tax WACC & 0.63 \\
Switzerland & UVEK & 2010 & $E P \_B M$ & Nominal post-tax WACC & 0.30 \\
UK & Ofgem & $2010-2015$ & $B M$ & Real Vanilla WACC & 0.35 \\
\hline
\end{tabular}

The data regarding Ireland and Romania concern transmission networks.

The $B M$-approach is by far the most common since incentive regulation has been introduced in many countries. Ex ante approaches considering individual capital structure, either with a cap or not, are rare (Germany, Romania). The equity ratio lies within a range of 30 up to $70 \%$, $40 \%$ being the most frequent value. The difference between network operators' $q$ in Table 2 and the values in Table 3 are often due to the fact that regulation authorities consider integrated energy utilities when identifying the values. ${ }^{11}$

\section{$5 \quad$ Sensitivity analysis}

In the following section, numerical results regarding the impact of bankruptcy cost, tax shield, return on debt and return on equity will be presented. The aim of this section is to discuss the link between EBIT-risk and leverage, to differentiate important and less important drivers of capital structure and to test whether this model leads to plausible results in view of the previous section. An exemplary parameterization of the model is used. In the basic scenario following values are set: $V^{r}=100, \mathrm{E}[x]=10, r^{e}=0.08, r^{d}=0.05, q^{r}=0.40$. The tax rates are set at $t_{c}=0.25, t_{p s}=0.24$ and $t_{p b}=0.21$, resulting in a tax shield of $0.22 .{ }^{12}$ The base case (highlighted with underlined letters) is repeated in each figure while one major parameter is changed.

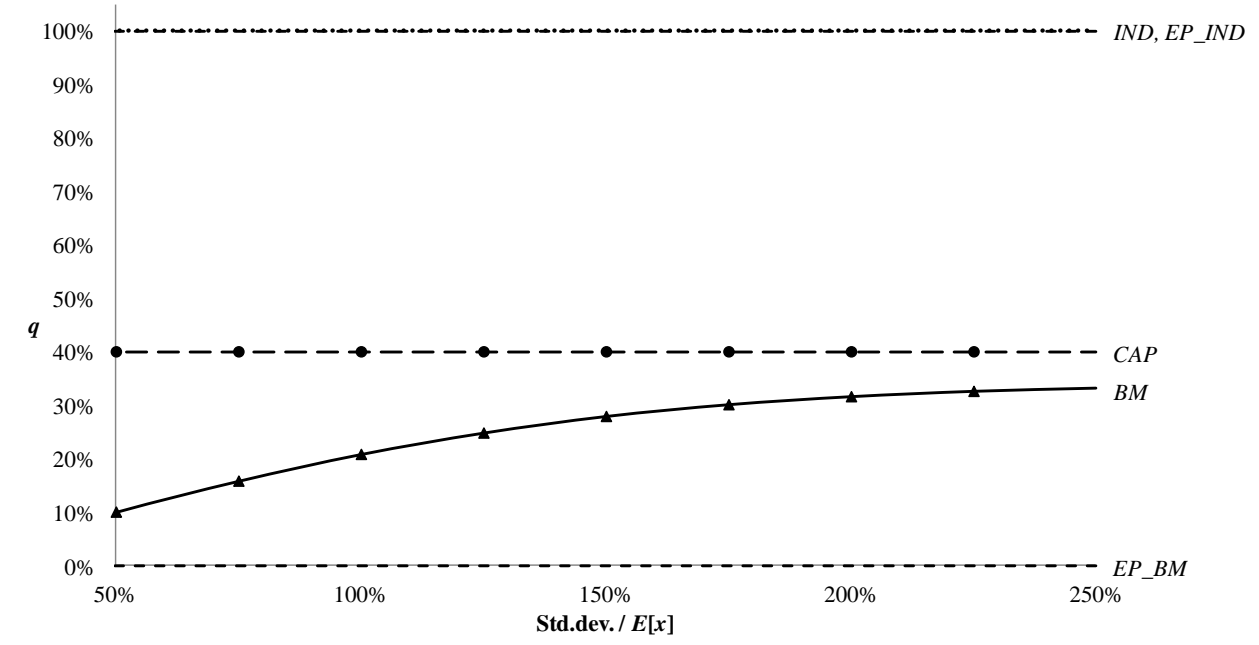

Figure 2: Standard parameterization

${ }^{11}$ Cf. for instance the reports of Frontier Economics (2008) for the German Bundesnetzagentur or the PwC (2009) report for Ofgem in the UK.

${ }^{12}$ Tax rates were taken from OECD tax database 2011. $\left(1-t_{p s}\right)\left(1-t_{c}\right)$ represents average from dividend tax rates statistics, countries with no personnel taxation were excluded. $\left(1-t_{c}\right)$ represents the average from corporate tax statistics. $\left(1-t_{p s}\right)$ was computed based on both values. $t_{p b}$ was estimated as average of flat taxes on interest income in 15 European countries. 
For the standard parameterization, the equity ratio in the $B M$ case increases with the standard deviation of the normal distribution (in opposition to observations by for instance Scott (1976) and Bradley et al. (1984), where the relationship is ambiguous). This might be due to the fact that no extremely high values for standard deviation were used. The $B M$ results indicate a range for the equity ratio between $10 \%$ and $30 \%$ which appears plausible compared to the numbers in Table 3 .

a) Bankruptcy cost
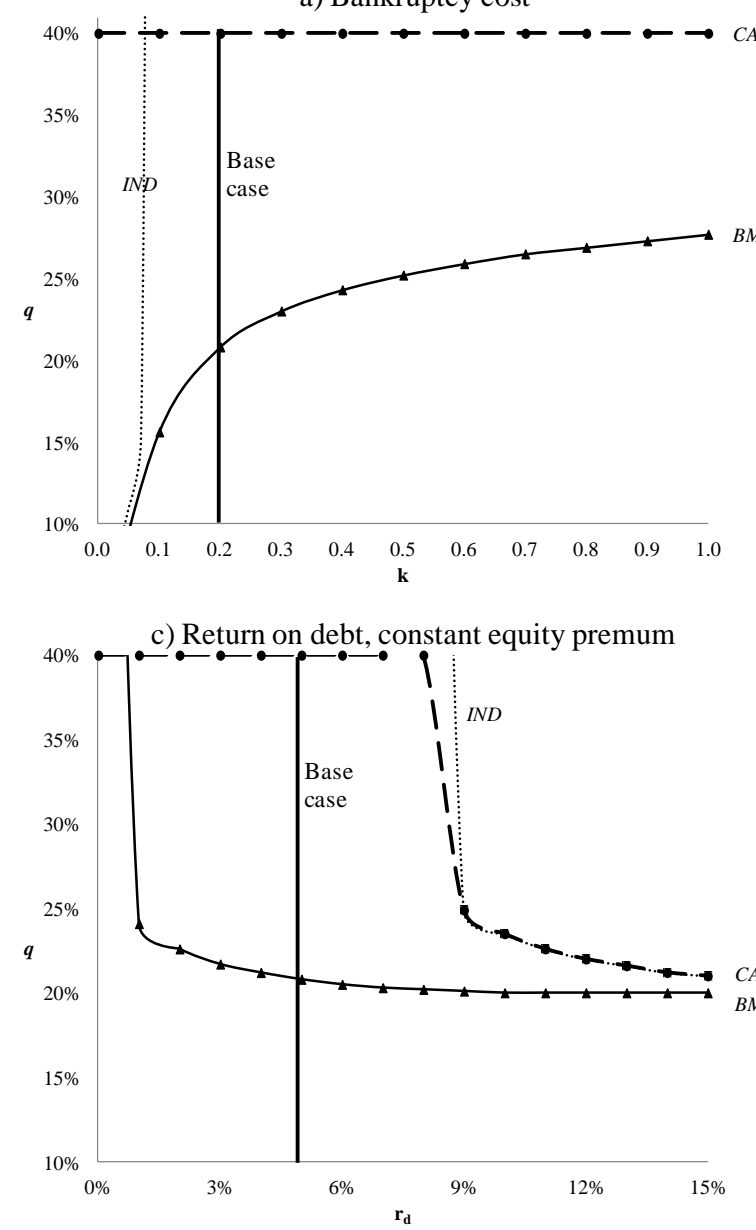

b) Tax Shield

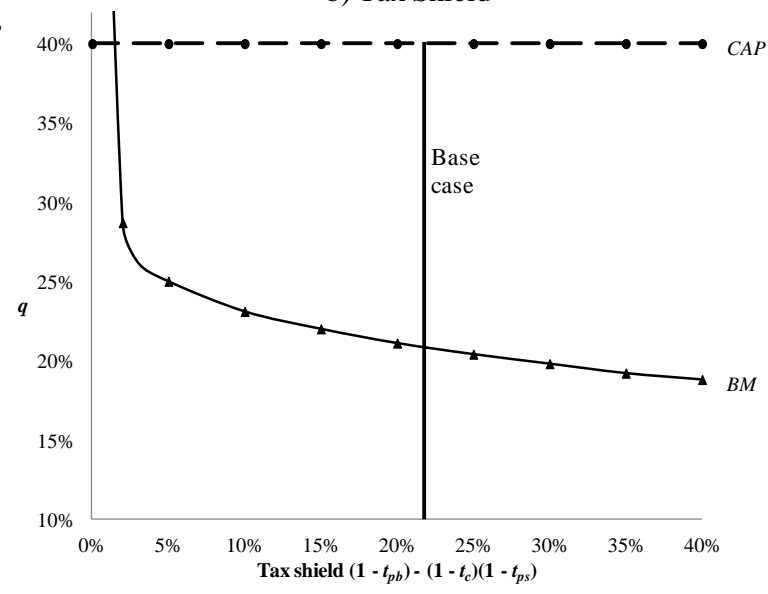

d) Return on equity

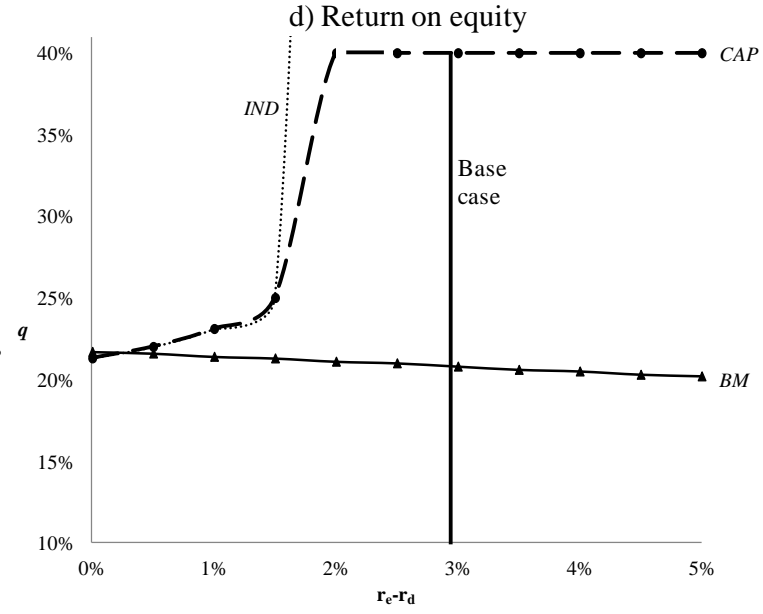

Figure 3: Bankruptcy costs and equity ratio

As expected, higher bankruptcy costs lead to more equity (Figure 3, section a). Under the given parameterization, IND (for all values of $k \geq 0.07$ ) and $E P$ will be solely equity financed. In the case of $C A P$, optimal equity ratio will equal the level of the cap. Regarding the magnitude of the impact of bankruptcy costs, the results are comparable to Bradley et al. (1984) who present equity ratio bandwidths between 5\% and 60\% (sigma being the driver of such high equity ratios).

A higher tax shield results in more leverage case (Figure 3, section b), but the curve is relatively flat. This can be explained by the fact that the tax shield only impacts the return on debt, while bankruptcy cost affect total value of the regulated asset base. ${ }^{13}$ For the tax shields defined, IND and $E P$ will always finance equity-based.

The same is true for the effect of return on debt. As expected, a higher return on debt leads to less equity (Figure 3, section c). Several effects, partially compensating each other, occur: First, expected total revenue $x$ increases (incentive for more debt). Second, bankruptcy risk increases due to a shifting of $b_{q}$ to the right (incentive for less debt). Third, the tax shield becomes more important (incentive for more debt). At a certain level of $r_{d}$, the importance of the

\footnotetext{
${ }^{13}$ This effect has been observed before. In Bradley et al. (1984), the introduction of a non-debt tax shield of $10 \%$ of firm value leads to an increase of the debt ratio by about 10 to $20 \%$. Given the tax rates used Bradley et al. (1984), a non-debt tax shield of $10 \%$ represents an increase of the tax shield by roughly $45 \%$ in our model.
} 
equity premium loses its dominance over the other effects and the equity ratio falls significantly below the cap.

The total effect of return on equity is comparable to the previously discussed effect regarding $r_{d}$ (Figure 3, section d). In the case of $B M$ an increase of return on equity raises total expected revenues as single effect making bankruptcy less likely. In the IND case, the impact of $r_{e}$ is reversed (increasing values reducing leverage) and much stronger because an increase of the equity premium provides additional incentives for equity.

Summarizing: In a $B M$ regime, bankruptcy costs are the most important driver for the capital structure. Tax shields are important, but the effect is limited because only actual benefits are taxed. Rates of return are less relevant for capital structure in the $B M$ case because they only lead to a second-order risk alteration. They are however highly relevant, if individual capital structures are considered (IND, CAP). All results are in line with results obtained in the comparative statics section. For the levels of standard deviation used, leverage decreases with bankruptcy risk.

\section{Implications for the Regulation of Heterogeneous Firms - Application to German Network Operators}

In many countries, network operators are structurally very different regarding the size of their activities. Especially, in Germany or Switzerland, several hundreds of very small network operators exist. Schober et al. (2011) discuss the impact of network structure regarding size and age structure on specific risk finding an important link between individual network structure and cash-flow risk of the firm. The analysis is built on an operations research framework optimizing replacement expenses modeling planned and premature replacements due to component failure. Failure events are linked to network age through the concept of failure rates. As these events are relatively rare, smaller network operators are characterized by a higher risk of having years in which very high expenses (in relation to the network operator's total cost) occur.

The results of Schober et al. (2011) are a building block for this paper to discuss the impact which cash flow risk variations related to firm size may have on capital structure. The standard network size $(\mathrm{n}=1)$ represents a distribution network operator (medium and low voltage) with a total line length (cable and overhead lines) of 2,000 km. Empiric research revealed that in Germany, $50 \%$ of electricity network operators are characterized by line lengths shorter than $200 \mathrm{~km}$ and $92 \%$ by line lengths shorter than $2,000 \mathrm{~km}$.

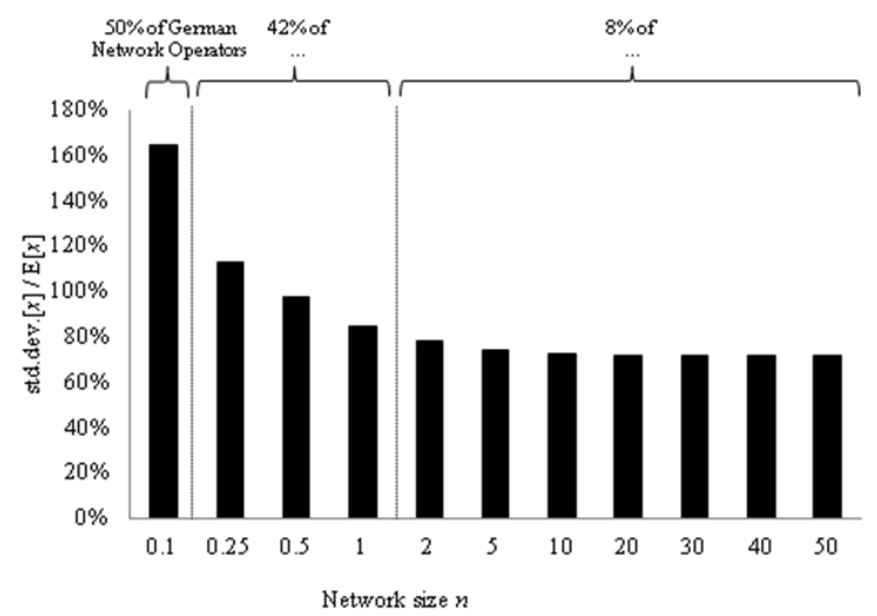

Figure 4: Network size of German Network operators and stochasticity of cash flows

A cashflow risk results, because due to incentive regulation, additional expenses cannot be passed through to customers via an increase of network tariffs. Total standard deviation in cash flows is modeled in Schober et al. (2011) and found to depend strongly on network 
size. ${ }^{14}$ The question arises, what these results would mean for optimal capital structure. The following figure connects the model in this paper with the results of Schober et al. (2011). The basic parameterization is the same as in section 5 .

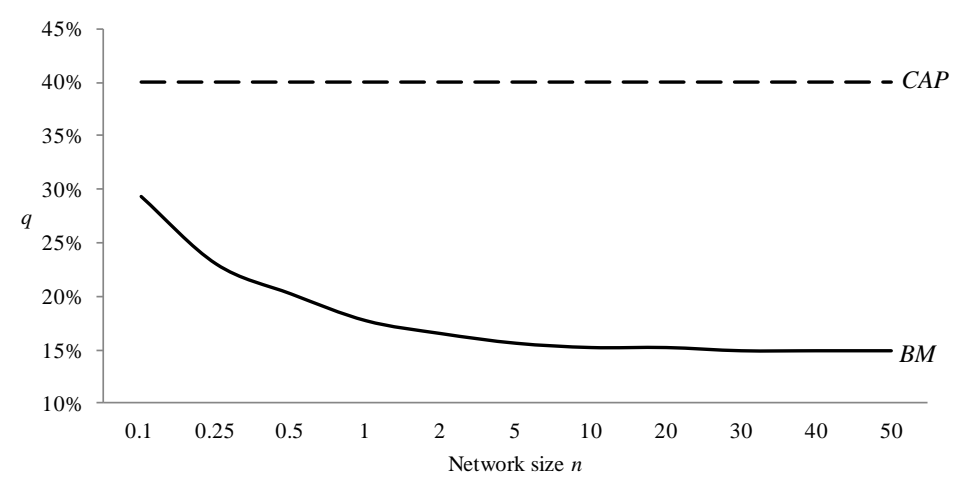

Figure 5: Optimal capital structure

Two facts are of major interest: the impact of size and the difference between the results for $B M$ and $C A P$.

With regards to the first fact: Bigger networks are characterized by lower stochasticity, leading to capital structures with equity ratios that are roughly $15 \%$ lower than the equity ratios of very small networks. This is of interest as many network operators for instance in Germany or Switzerland are of a very small firm size and thus require higher equity ratios. Assuming an equity ratio that is $15 \%$ higher for smaller network operators and a post-tax difference of $3 \%$ between return on equity and return on debt, the post-tax WACC would have to be increased by $0.45 \%$.

With regards to the second fact: The German regulator has chosen a CAP approach signifying that network operators choose a capital structure close to the cap at $40 \%$ equity, a phenomenon which is observable in practice. Bigger network operators that would normally opt for less equity (around 15 to 25\%) use more equity than required. From a customer's perspective, the question of $B M$ or $C A P$ is irrelevant because capital cost remunerated via network tariffs will be the same, if the regulatory cap is set at a benchmark level. ${ }^{15}$ From a network operator's perspective it is still relevant, because in a BM scheme, not required equity could be invested otherwise and thus additional profits may be achieved. If the regulation authority would however opt to decrease $q^{R}$, social welfare could be increased and incentives for merging networks building bigger network operators would be reinforced.

\section{Conclusion}

The aim of this paper is to compare different approaches to capital structure regulation. Several articles such as Spiegel (1994), Spiegel and Spulber (1994) and Fraja and Stones (2004) use different models to analyze optimal capital structure under regulation. In this article, five types of capital structure regulation and their impact on the optimal capital structure are discussed. The main contribution of this paper is the formulation of a general model that permits modeling the impact of different types of capital structure regulation on optimal capital structure. Furthermore, this article discusses a capital structure cap approach used by some regulatory agencies (Germany, Belgium) that has not been a topic in research so far.

\footnotetext{
${ }^{14}$ The resulting level of cashflow risk also depends on assumptions regarding stochasticity of other costs and revenues. Both were assumed to be $10 \%$ of expected value to give an indication as realistic as possible. If both effects were excluded, than total standard deviation would asymptotically decline to zero for large network operators with the result of showing even higher differences in capital structure for different sizes. If one excludes the additional effects comparing the sizes $n=0.1$ and $n=10$, the difference in optimal capital structure would increase from about $15 \%$ to $23 \%$.

${ }^{15}$ In the case of $C A P$, the network operator will go for the cap equity ratio. In the case of $B M$, the WACC will be calculated as if the network operator had chosen a cap equity structure. The network cost of capital is consequently the same.
} 
The most common form in incentive regulation is the benchmark capital structure approach, in which a predefined equity ratio is used to compute the weighted average cost of capital. This model is the most popular model among European regulators leading to a capital structure optimizing the trade-off between potential bankruptcy and value of the tax shield. It does not give any specific regulatory incentive for any predetermined capital structure and influences only indirectly by adapting cashflow risk. The approach of considering individual capital structure in an ex-ante setting is far less popular. If the value of the equity premium is significant, it leads to a pure equity-financing strategy. Anticipating this effect, the German regulator introduced a cap model for regulatory equity, in which the individual capital structure is considered until an equity cap is reached. Beyond that cap, the benchmark structure is considered. Given a significant equity premium, incentives are strong to choose an equity ratio close to that cap. As such, the cap is an effective instrument to incentivize a predetermined capital structure. In ex-post regulation, bankruptcy poses no real threat thus leading to take on more financial risks. The reduction of risk, the Peltzman effect, is due to a buffering of shocks achieved by the regulatory regime. The consequence was for instance observed throughout the introductory period of regulation in the US between 1912 and 1922 by Taggart (1985): firms significantly increased leverage as a reaction. One possible approach in an ex-post setting is to remunerate the regulatory asset value with a predefined benchmark cost of capital. This creates an incentive to reduce equity to zero, minimizing the average cost of capital and maximizing the tax shield. If individual capital structures are considered in an ex-post regime, the equity premium will give incentive to maximize equity if it is more important than the tax shield. A cap in this case would work the same way it does in an ex-ante regulation and give strong incentives to adapt the predetermined cap as target equity ratio. So if one excludes all other effects from consideration (e.g. pecking-order aspects), ex-post regulation may lead to three possible strategies: no equity, equity at cap-level, pure equity. These results contradict the results of Spiegel (1994) and Spiegel and Spulber (1994) due to the fact that in their mod$\mathrm{el}$, regulated firms threaten the regulator in order to achieve higher revenues.

The model may be extended in future research to include also non-debt tax shields. Moreover, modeling in a dynamic context may provide further insights about the transition paths firms may adopt to adjust capital structure under regulation. Additionally, in-depth cross-country empirical studies on the impact of switching from ex-post to ex-ante regulation are desirable to confirm (or refute) the analytical results established here. 


\section{Appendix}

In order to investigate whether an interior solution to the optimal capital structure problem exists, the monotonicity and sign changes of the first derivative are scrutinized

$$
\begin{aligned}
& \frac{\partial V^{B M}}{\partial q}=\frac{1}{r_{0}}\left[-f\left(b_{q}\right) \cdot\left(-V^{R}\left(1+r_{d}\right)\right) \cdot k V^{R}\right. \\
& \quad+\left[\left(1-t_{p b}\right)-\left(1-t_{p s}\right)\left(1-t_{c}\right)\right] r_{d} V^{R}\left[-1+F\left(b_{q}\right)-(1-q) f\left(b_{q}\right)\left(-V^{R}\left(1+r_{d}\right)\right)\right] \\
& \left.\quad-\left(1-t_{p s}\right)\left(1-t_{c}\right) b_{q} \cdot f\left(b_{q}\right) \cdot\left(-V^{R}\left(1+r_{d}\right)\right)\right]
\end{aligned}
$$

The second derivative in the case of $B M$ is given by:

$$
\begin{aligned}
& \frac{\partial}{\partial q}\left(\frac{\partial V^{B M}}{\partial q}\right)=\frac{1}{r_{0}}\left[f^{\prime}\left(b_{q}\right)\left(-V^{R}\left(1+r_{d}\right)\right)\left[-k V^{R}\right]\right. \\
& +\left[\left(1-t_{p b}\right)-\left(1-t_{p s}\right)\left(1-t_{c}\right)\right] r_{d} V^{R}\left(-V^{R}\left(1+r_{d}\right)\right)\left[2 f\left(b_{q}\right)-(1-q) f^{\prime}\left(b_{q}\right)\right] \\
& -\left(1-t_{p s}\right)\left(1-t_{c}\right)\left(-V^{R}\left(1+r_{d}\right)\right)\left[f^{\prime}\left(b_{q}\right) b_{q}+f\left(b_{q}\right) \cdot\left(-V^{R}\left(1+r_{d}\right)\right)\right]
\end{aligned}
$$

Since $q$ is occurs as part of in $F\left(b_{q}\right)$ and $f\left(b_{q}\right)$, it is not possible to solve the first order condition for an inner optimum for $q$. Therefore, Bolzano's theorem will be used to verify, if an optimal capital structure exists. Three conditions have to be fulfilled in order to prove the existence of an inner solution. First, for low values of q, $\partial V^{B M} / \partial q>0$. Second, for higher values of q, $\partial V^{B M} / \partial q<0$. Third, negative monotonicity must be given, thus $\partial\left(\partial V^{B M} / \partial q\right) \partial q \leq 0$. This assures that an inner maximum of the firm value exists. We analyze $\partial V^{B M} / \partial q$ line by line in order to separate effects.

Table: First and second derivative of market value

\begin{tabular}{llll}
\hline \hline Formula (14) - Line & $\partial \boldsymbol{V} / \partial \boldsymbol{q}(\boldsymbol{q}=\mathbf{0})$ & $\partial \boldsymbol{V} / \partial \boldsymbol{q}(\boldsymbol{q}=\mathbf{1})$ & $\partial \boldsymbol{V}^{2} / \hat{\boldsymbol{\partial}}^{2} \boldsymbol{q}$ \\
\hline \hline 1 & $>0$ & $=0$ & $<0$ \\
2 & $\geq 0^{* *}$ & $<0$ & $<0$ \\
3 & $<0$ & $=0$ & $?$ \\
Total & $>0^{*}$ & $<0$ & $<0^{*}$ \\
\hline indicates that condition (15) is required for the proposition to hold. This is always true for $q=0$. \\
${ }^{*}$ indicates that $F\left(b_{q}\right) \geq 0.5$ for $q=0$ is a necessary condition.
\end{tabular}

This proves that under certain restrictions, one inner optimal solution for the capital structure exists.

$$
\begin{aligned}
& -\frac{\partial F\left(b_{q}\right)}{\partial q}(q=0) \geq 1-F\left(b_{q} \mid q=0\right) \Leftrightarrow-F\left(b_{q} \mid q=0\right)+F\left(b_{q} \mid q=1\right) \geq 1-F\left(b_{q} \mid q=0\right) \\
& \Leftrightarrow 0 \geq 1-2 F\left(b_{q} \mid q=0\right) \Rightarrow F\left(b_{q} \mid q=0\right) \geq 0.5
\end{aligned}
$$




\section{List of Symbols}

$b_{q} \quad$ Bankruptcy limit

$D \quad$ Book value of debt

E Book value of debt

$m \quad$ Regulatory margin on $o$

$o \quad$ Operational expenditures

$q \quad$ Equity ratio

$q^{r} \quad$ Equity target ratio set by regulator

$r_{e} \quad$ Return on equity

$r_{d} \quad$ Return on debt

$r_{v} \quad$ Weighted average cost on capital

$r_{0} \quad$ Capitalization rate

$t_{c} \quad$ Corporate tax

$t_{p b} \quad$ Personal tax on interests from bonds

$t_{p s} \quad$ Personal tax on dividends and stock gains

$x \quad$ Earnings before interest and taxes

\section{References}

Altman, E. I. (1984): A Further Empirical Investigation of the Bankruptcy Cost Question; The Journal of Finance (VOL. 40); pp.1067-1089

Baxter, N. D. (1967): Leverage, Risk of Ruin and the Cost of Capital; The Journal of Finance (VOL. 22); pp.395-493

Bortolotti, B.; Cambini, C.; Rondi, L.; Spiegel, Y. (2008): Capital Structure and Regulation: Do Ownership and Regulatory Independence Matter?; Working Paper (13th of December 2008)

Bradley, M.; Jarrel, G.; Kim, E. H. (1984): On the Existence of an Optimal Capital Structure; The Journal of Finance (VOL. 39); pp.857-877

Brennan, M. J.; Schwartz, E. S. (1984): Optimal Financial Policy and Firm Valuation; The Journal of Finance (VOL. 39); pp.593-607

Castanias, R. (1983): Bankruptcy Risk and Optimal Capital Structure; The Journal of Finance (VOL. 38); pp.1617-1635

Chen, C.; Fanara, P. (1992): The Choice Among Long-Term Financing Instruments for Public Utilities; The Financial Review (VOL. 27); pp.431-465

Dasgupta, S.; Nanda, V. (1993): Bargaining and brinkmanship: Capital structure choice by regulated firms; International Journal of Industrial Organization (VOL. 11); pp.475-497

De Fraja, G.; Stones, C. (2004): Risk and Capital Structure in the Regulated firm; Journal of Regulatory Economics (VOL. 26); pp.69-84

DeAngelo, H.; Masulis, R. W. (1980): Optimal capital structure under corporate and personal taxation; Journal of Financial Economics (VOL. 8); pp.3-29

Elton, E. J.; Gruber, M. J. (1971): Valuation and the Cost of Capital for Regulated Industries; The Journal of Finance (VOL. 26); pp.671-670

Elton, E. J.; Gruber, M. J. (1972): Valuation and the Cost of Capital for Regulated Industries: Reply; The Journal of Finance (VOL. 27); pp.1150-1155

Frank, M. Z.; Goyal, V. K. (December 8, 2007): Trade-Off and Pecking Order Theories of Debt; Working Paper, available at SSRN: http://ssrn.com/abstract=670543 (); pp.

Frontier Economics (2008): Ermittlung des Zuschlags zur Abdeckung netzbetriebsspezifischer Wagnisse im Bereich Strom und Gas; Report for Bundesnetzagentur (June)

Gordon, M. J. (1967): Some Estimates of the Cost of Capital to the Electric Utility Industry, 1954-57: Comment; American Economic Review (VOL. 57); pp.1267-1278

Harris, M, Raviv, A. (1991): The Theory of Capital Structure; The Journal of Finance (VOL. 46); pp.297-355

Jaffe, E.; Mandelker, G. (1976): The Value of the Firm Under Regulation; The Journal of Finance (VOL. 31); pp.701-713

Kraus, A.; Litzenberger, R.H. (1973): A State-Preference Model of Optimal Financial Leverage; The Journal of Finance (VOL. 28); pp.911-922 
Miller, M. H. (1977): Debt and Taxes; The Journal of Finance (VOL. 32); pp.261-275

Miller, M. H.; Modigliani, F. (1958): The Cost of Capital, Corporation Finance and the Theory of Investment; The American Economic Review (VOL. 53); pp.261-297

Miller, M. H.; Modigliani, F. (1961): Dividend Policy, Debt and the Valuation of Shares; The Journal of Business (VOL. 34); pp.411-433

Miller, M. H.; Modigliani, F. (1963): Corporate Income Taxes and the Cost of Capital: A Correction; The American Economic Review (VOL. 53); pp.433-443

Miller, M. H.; Modigliani, F. (1966): Some Estimates of the Cost of Capital to the Electric Utiliy Industry, 19541957; The American Economic Review (VOL. 56); pp.333-391

Myers, S. C. (1984): The Capital Structure Puzzle; The Journal of Finance (VOL. 39); pp.575-592

Peltzman, S. (1976): Toward a More General Theory of Regulation; Journal of Law and Economics (VOL. 19); pp.211-240

PwC (2009): Advice on the cost of capital analysis for DPCR5; Report for OFGEM

Rao, R.; Moyer, R. C. (1994): Regulatory Climate and Electric Utility Capital Structure Decisions; Financial Review (VOL. 29); pp.97-124

Robichek, A. A.; Higgins, R. C.; Kinsman, M. (1973): The Effect of Leverage on the Cost of Equity Capital of Electric Utilities Firms; The Journal of Finance (VOL. 28); pp.353-367

Sanyal, P.; Bulan, P. T. (2005): Regulatory Risk, Market Risk and Capital Structure: Evidence from U.S. Electric Utilities; Working Paper

Schober, D.; Schaeffler, S.; Weber, C. (2011): Implicit Discrimination in Regulation: The Role of Idiosyncratic Risk due to Size and Age Distribution of Electricity Networks; Working Paper

Scott, J. H. (1976): A Theory of Optimal Capital Structure; Bell Journal of Economics (VOL. 7); pp.33-54

Spiegel, Y. (1994): The capital structure and investment of regulated firms under alternative regulatory regimes ; Journal of Regulatory Economics (VOL. 6); pp.297-319

Spiegel, Y., Spulber, D. F. (1994): The capital structure of a regulated firm; Rand Journal of Economics (VOL. 25); pp.424-440

Taggert, R. A. (1981): Rate-of-Return Regulation and Utility Capital Structure Decisions; The Journal of Finance (VOL. 36); pp.383-393

Taggert, R. A. (1985): Effects of Regulation on Utility Financing; The Journal of Finance (VOL. 33); pp.257276

Warner, J. B. (1977): Bankrupty Costs: Some Evidence; The Journal of Finance (VOL. 32); pp.337-347

Weiss, L. A. (1990): Bankruptcy resolution: Direct costs and violation of priority of claims; Journal of Financial Economics (VOL. 27); pp.285-314 